\title{
NASA System-Level Design, Analysis and Simulation Tools Research on NextGen
}

Jorge Bardina

NASA Ames Research Center, CA 94035

Copyright (C) 2011 SAE International

\begin{abstract}
A review of the research accomplished in 2009 in the System-Level Design, Analysis and Simulation Tools (SLDAST) of the NASA's Airspace Systems Program is presented. This research thrust focuses on the integrated system-level assessment of component level innovations, concepts and technologies of the Next Generation Air Traffic System (NextGen) under research in the ASP program to enable the development of revolutionary improvements and modernization of the National Airspace System. The review includes the accomplishments on baseline research and the advancements on design studies and system-level assessment, including the cluster analysis as an annualization standard of the air traffic in the U.S. National Airspace, and the ACES-Air MIDAS integration for human-in-the-loop analyzes within the NAS air traffic simulation.
\end{abstract}

\section{INTRODUCTION}

As the air traffic demand increases to levels that are not sustainable by the air traffic management system, NASA has been mandated by Congress to support the development and implementation of the Next Generation Air Transportation System (NextGen) of the U.S.A. National Air Space (NAS). This national effort is led by the Joint Planning and Development Office (JPDO) " to retain U.S. leadership in global aviation, expand capacity, ensure safety, protect the environment, ensure our national defense, and secure the nations" [1].

Although the estimated air traffic demand is subject to forecasts under present economic uncertainties, the benefits of NextGen are important as the latest 2011 report of the Federal Aviation Administration entitled "FAA's NextGen Implementation Plan" [2] states:

"NextGen is a comprehensive overhaul of our National Airspace System to make air travel more convenient and dependable, while ensuring your flight is as safe, secure and hassle free as possible. ... Our latest estimates, which are sensitive to traffic and fuel price forecasts, indicate that by 2018, NextGen will reduce total delays (in flight and on the ground) by about 35 percent compared with what would happen if we did nothing. That delay reduction will provide, through $2018, \$ 23$ billion in cumulative benefits to aircraft operators, the traveling public and the FAA. In the process, we will save about 1.4 billion gallons of aviation fuel during this period, reducing carbon dioxide emissions by 14 million tons."

NASA as a partner agency has established the Airspace Systems Program (ASP) to lead the foundational research to enable the development of revolutionary improvements in support of NextGen. This research is mainly conducted at Ames Research Center and Langley Research Center in collaboration with industry research contracts, academia research agreements, and other federal agency cooperative agreements.

\section{AIRSPACE SYSTEMS PROGRAM}

The Airspace Systems Program (ASP) focuses on new concepts, capabilities, and technologies in fundamental air traffic management research to enable significant increases in capacity, efficiency, and flexibility on the National Airspace System (NAS). ASP has recently been re-organized into two projects: Concepts and Technology Development (CTD), formerly NextGen-Airspace, and Systems Analysis, Integration \& Evaluation (SAIE), formerly NextGen-Airportal [3, 4]. 
The NextGen CTD Project focuses on developing capabilities to significantly increase air space and surface terminal capacity, efficiency and safety. New fundamental concepts and technologies are being developed at the component level in the following areas of research focus: Traffic Flow Management (TFM) to maximize national-airspace throughput with new processes to address the demand and capacity imbalances from weather effects and system wide uncertainties; Dynamic Airspace Configuration (DAC) to increasing system capacity by bringing to bear available airspace and controller resources and capacity to changes in traffic demand; Separation Assurance (SA) to increase capacity through higher levels of automation, scheduling sequencing, merging, and spacing, and ensure safe, on-time, fuel-efficient, en-route flight while allowing for reduced distance between aircraft, under increased air-traffic volumes and varying weather conditions; Super Density Operations (SDO) to optimize timely arrivals, departures and surface operations through fuel-saving "continuous descents," arrival/departure-time management, route modification and adaptive speed control; and Safe and Efficient Surface Operations (SESO) to achieve the most effective pace for such surface operations as taxiing, departures, landings and gate arrivals.

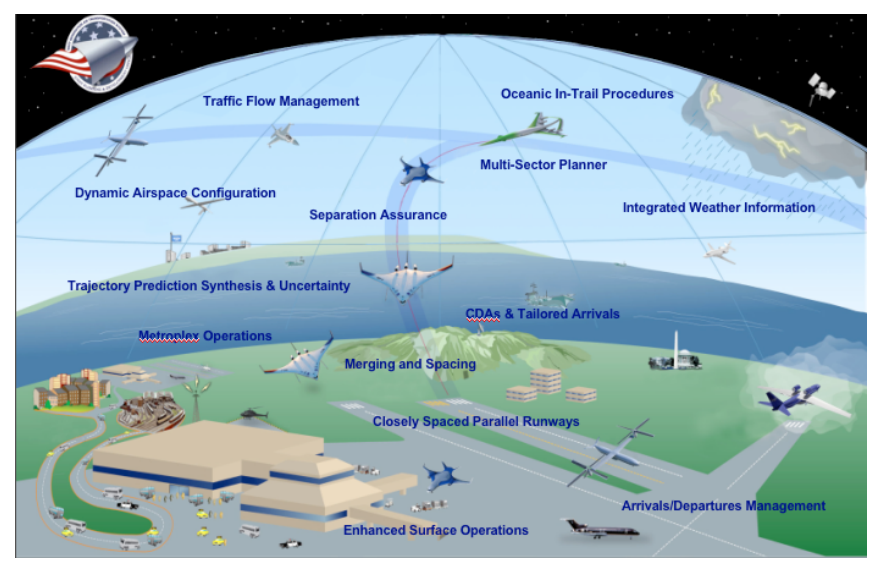

Figure 1 - Areas of Research Focus of the Airspace Systems Program.

The NextGen SAIE Project focuses on the integrated systems analysis of the fundamental concepts, technologies and procedures to determine their NextGen viability "through evaluation in relevant environments, providing integrated solutions, characterizing airspace system problem spaces, defining innovative approaches, and assessing the potential system impacts and design ramifications of the Program's portfolio." This project has three areas of research focus: Integration, Evaluation and Transition (IET) to evaluate concepts \& technologies of the program in relevant environments; Interoperability Research (IR) to research the integration and the interaction of multiple fundamental concepts and technologies within the research portfolio across the research focus areas of the program; and System and Portfolio Analysis (SPA) to perform systems studies to identify the system benefits or impacts of the program's concepts and technologies to the program and to researchers and developers.

\section{SYSTEM-LEVEL DESIGN, ANALYSIS AND SIMULATION TOOLS}

System-Level Design, Analysis and Simulation Tools (SLDAST), formerly a research focus area of the NextGen-Airspace Project, is currently a major component of the SAIE Project. This paper presents a comprehensive view of the 2008 SLDAST milestones and accomplishments.

In 2009, SLDAST addressed the system-level design, analysis and simulation requirements of the ASP Program. Research focused on the development of simulations and requirements needed to achieve a comprehensive understanding of the benefits and the integrated benefits of the future NextGen technologies and concepts developed in the program. The challenges of the research is increased by the programmatic need of early-on assessments of selected future technologies and concepts under study in the different research focus areas of the program, their integration on the National Airspace System (NAS) that has naturally evolved through the years into a very complex system with multiple stakeholders sustaining diverse and conflicting objectives, and the need to reach an understanding of the complex interactions in the system with different traffic demands and capacity levels. The technological advances will undoubtedly change the NAS, implying that the changes in NextGen behavior have to be determined and assessed.

Presently the insertion of new technology and procedures into the NAS is normally conducted at the component level using prototyping and iterative human-in-the-loop simulation with limited or no system-level design constraints that effect the design or even provide feedback to the design of a new fundamental concept or technology. SLDAST has been conceived to provide a common foundation to the program and early information on NextGen concepts and technologies. To address the complexity of the system, 
SLDAST has defined a set of different levels of research focus, a baseline research on common definitions, scenarios, metrics and assumptions including; a set of design studies across different research focus areas of the program; and a set of system-level assessments of multiple NextGen fundamental concepts and technologies. The following Fig. 2 shows the SLDAST program milestones with the baseline research on top, the system-level assessments in the middle, and the design studies at the bottom.

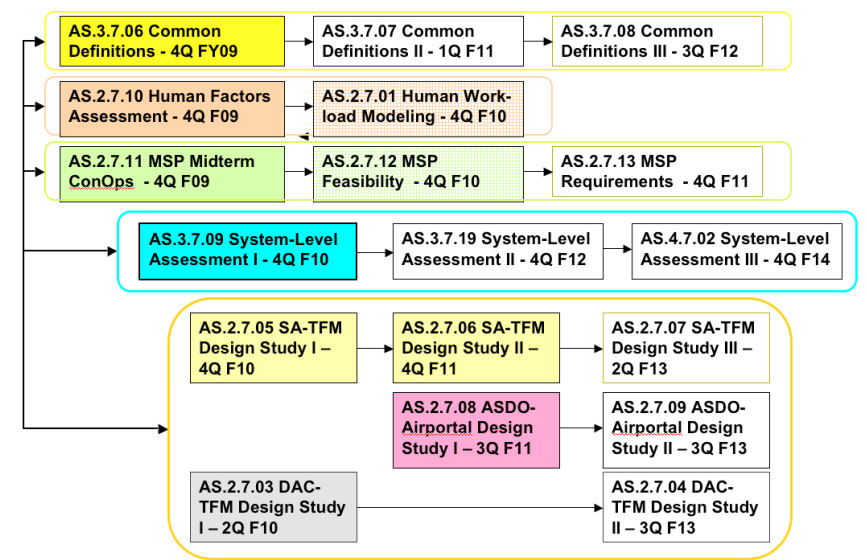

Figure 2-SLDAST Milestones.

A common programmatic environment in the simulation of the design studies and the system-level assessments is the Airspace Concept Evaluation System (ACES) [5] being developed at Ames Research Center and funded by SLDAST to enable the evaluation of the system-wide effects of the NAS and the proposed NextGen concepts and technologies to increase capacity, reduce delays, and accommodate the forecast growth in air traffic. It will also incorporate a large set of improvements on surface and air capacity envisioned within NextGen technologies, as it is described in the JPDO's NextGen Implementation Plan and the NextGen concepts and technologies [6-8].

A brief description of the SLDAST areas of research focus is included below,:

- Baseline Research: to assess the benefits of NextGen concepts and technologies is necessary to define and develop the supporting common scenarios and simulation models based on the NextGen concepts and technologies and the NextGen Implementation Plan developed by JPDO, including their expected traffic demand levels and their different weather conditions; to define the common assumptions of the studies on time frames, avionics, aircrafts, demand growth, separation assurance, weather, network enablers, and all changes due to the NextGen technologies; and to define the common metrics on capacity, throughput, efficiency, predictability, risk, reliability, safety, system-wide interoperability, and environmental requirements; to define the human factors each study will require to support the design studies and the system-level performance assessments. The baseline studies also include the continued development of the ACES simulation tool of NAS, and the different modifications needed to represent NextGen concepts and technologies, including human factors in-the-loop. 


\section{Common Scenario Generation}
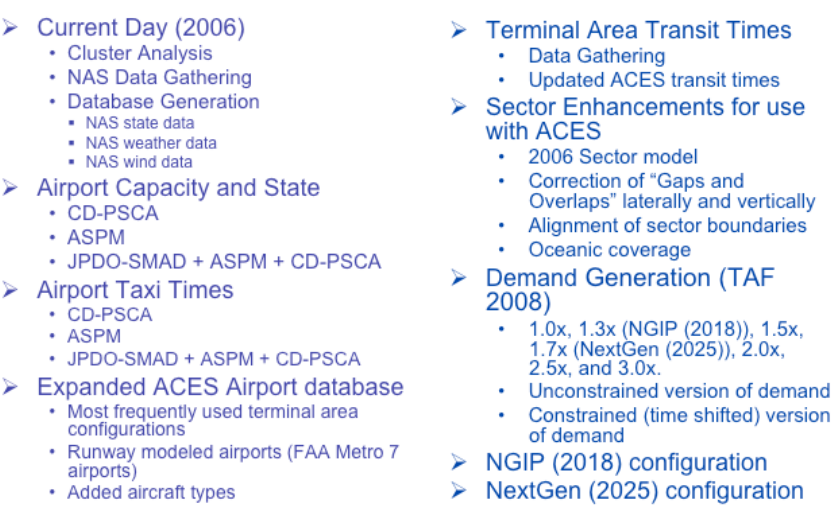

Figure 3 - High-level Common Scenario Generation

This research includes a large set of common scenarios (a general description is shown below in Fig. 3), common metrics, and assumptions used across different research focus areas.

A study study on metrics was conducted under the Common Definitions milestone. This research defined a common set of metrics for measuring NAS and NextGen performance, and "the metrics are directly traceable to JPDO NextGen goals and objectives and will be useful for measuring the progress of ASP research in enabling NextGen” [9].

The SLDAST research also includes an emphasis on human factors. An specific Human Factors Assessment milestone was established to develop the technology needed to include these factors into the NAS analysis. The main technical objective was the identification and prioritization of the NextGen Human Factors issues vetted by the relevant human performance research community. The principal technical challenges on this research were the inherent complexity of the NextGen operations, the requirement of comprehensive definitions of the NextGen concepts, including a clear specification of the concept implementations and functions, the context definition of the operational concepts, and the generalization to a systemlevel complex environment; and most importantly the development of methodologies and specific tools to enable the integration of human factors considerations in-the-loop of the NAS within a NextGen context [10-12].

Another significant research on human factors was the development of human workload models suitable for use in fast-time simulations and their integration into the ACES fast-time NAS simulation. This capability supports the NAS evaluations including the concepts on the human operators who are charged with the responsibility of executing and managing operations, a primary factor to determine the capacity potential of an airspace management concept. Thus, part of the assessment of each alternative concept concerns whether the human operators can accomplish the work directed to them by the NextGen concept. This project has focused on the integration of the human workload simulation system called Air MIDAS with the ACES simulator of the NAS air traffic.. 

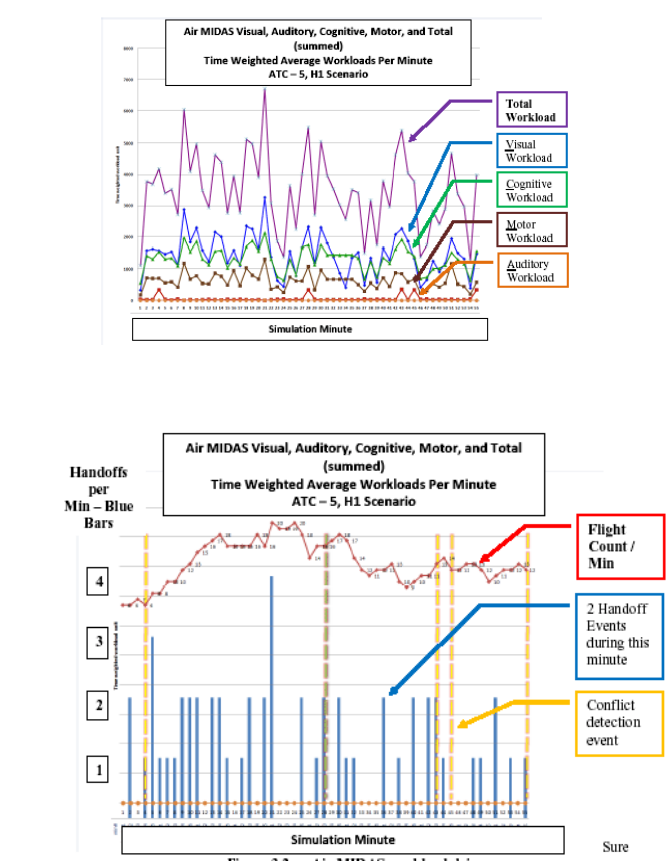

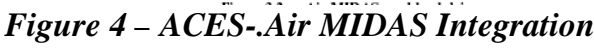

Figure 4 shows the results of an ACES-Air MIDAS integration experiment. The simulation airspace was a modified Dallas-Fort Worth Center (ZFW) airspace with three controllers working on three high-altitude sectors with increased sector size and complexity. The top figure shows the workload of one operator for one of the six test scenarios, and also shows the correlation among the visual, cognitive, motor and auditory workloads of one operator. The bottom figure shows the handoff and the conflict detection and resolution workload drivers of one operator with the total number of aircrafts in the sector. The experiment shows strong indications on the validation of the ACES-Air MIDAS integration as a tool for assessing human workload capacity and different aspects of controller performance.

- Design Studies: to assess the benefits of the interoperability of NextGen concepts of different research focus areas is necessary to conduct interaction studies between multiple research areas. The selected interaction studies include key interactions between NextGen TFM-DAC, TFM-SA, and ASDO-Airportal concepts. For example, TFM and DAC interactions will study how much capacity can be achieved through airspace boundary adjustment before the demand must be managed for demand-capacity imbalance problem. These studies will provide the foundation for the more comprehensive system-level assessments. Several NextGen concepts were analyzed to study the possibility to include them in the design studies, and based on their level of development the research in 2009 focused on the ACES implementation of the high altitude airspace resectorization of the Dynamic Airspace Unit concept [13] and the resectorization based on Voronoi Diagrams and Genetic Algorithms [14], the strategic traffic flow management "LP Optimization" concept [15], and the strategic separation assurance of the en route Advanced Airspace Concept [16, 17].

- System-Level Assessments: of fundamental NextGen concepts including relevant NextGen technologies to determine the performance assessments identifying their collective impact. The system-level performance assessments are required to include key concepts, not just point solutions; for example, the inclusion of both airborne and ground-based separation management functions.

Table 1 - System-Level Assessment I: NextGen Concepts and Enabling Technologies.

\begin{tabular}{|l|l|}
\hline RFA & NextGen Concepts \\
\hline SLDAST & Weather rerouting \\
\hline DAC & $\begin{array}{l}\text { High altitude airspace configuration } \\
\text { (Resectorization): Dynamic Airspace Unit }\end{array}$ \\
\hline
\end{tabular}




\begin{tabular}{|c|c|}
\hline & $\begin{array}{l}\text { (DAU) / (Resectorization Voronoi Diagrams \& } \\
\text { Genetic Algorithms) } \\
\text { Not included: Airspace classification. Corridors }\end{array}$ \\
\hline TFM & $\begin{array}{l}\text { Strategic TFM (LP Optimization) } \\
\text { Not included: Probabilistic methods, } \\
\text { Collaborative methods, Weather products, } \\
\text { Tactical TFM (Weather and congestion } \\
\text { avoidance) }\end{array}$ \\
\hline SA & $\begin{array}{l}\text { Strategic SA: En Route Advanced Airspace } \\
\text { Configuration (AAC) } \\
\text { Not included: Tactical SA (TSAFE), Airborne } \\
\text { strategic SA (Genetic Algorithm), Collision } \\
\text { avoidance (TCAS) }\end{array}$ \\
\hline ASDO & $\begin{array}{l}\text { TMA/Merging \& Spacing, Runway threshold } \\
\text { scheduler and router: Very Closely Spaced } \\
\text { Parallel Runway Operations (VCSPRO), RNAV } \\
\text { and RNP routing,Weather mitigation } \\
\text { Not included: OPD/CDA, Flight deck merging } \\
\text { and spacing, Conformance monitor, CD\&R }\end{array}$ \\
\hline SESO & $\begin{array}{l}\text { Pushback Scheduler (TBSO), Departure } \\
\text { Operation Planning (TBSO), Taxi Operation \& } \\
\text { Optimization Planner (TBSO) } \\
\text { Not included: Conformance monitor, CD\&R, } \\
\text { Environmental planner }\end{array}$ \\
\hline CADOM & $\begin{array}{l}\text { Runway Configuration Management (RCM), Not } \\
\text { included: Combined Arrival/ Departure Runway } \\
\text { Scheduling (CADRS) }\end{array}$ \\
\hline AMI & $\begin{array}{l}\text { Not included: Metroplex operation planner, } \\
\text { Metroplex airport configurations }\end{array}$ \\
\hline SLDAST & $\begin{array}{l}\text { Weather Forecast and Capacity Estimation } \\
\text { (WSI) }\end{array}$ \\
\hline
\end{tabular}

The System-Level Assessments address multiple experiments within and across multiple fundamental concepts of the different areas of research focus of the program. The selected future concept elements are identified and prioritized through a set of individual evaluation assessments and integrated in a system-wide NAS architecture to assess their individual and integrated benefits as a function of increasing air traffic demand and different levels of weather. The integration of the NextGen concepts listed in Table 1 in ACES was initiated in 2009, together with the development of the NextGen scenarios required to perform the ACES simulations and their analysis. A large set of research on the different research focus areas of the program was accomplished to support the requirements for system-level assessment, and these accomplishments are reported independently and will be cited in the future program milestones [18-45].

To perform annualized assessments is necessary to develop a method that can characterized a typical year in the NAS. To achieve this objective, a cluster analysis of the National Air Space (NAS) has been developed to determine annualized statistics of the air traffic [46]. The approach is based on cluster analysis and uses principal component analysis and K-means techniques. This research recommends specific historical days to use both for baseline simulations and for annualization statistics, as a well-founded frame of reference of the air traffic in the NAS. In this analysis, a Principal Component Analysis technique was used to analyze the different performance metrics of each day in the NAS historical data from 2002 through 2006, and to select the most relevant independent metrics that define best each day, where each day was characterized based on different performance metrics defining the elements of the different RFAs. The analysis included 112 NAS performance metrics and the analysis reduced the set to eight key independent metrics. These key metrics are ground delay program delay minutes, ground stop delay minutes, average ground delay minutes, scheduled arrival delay minutes, count of on-time scheduled arrivals, airborne delay minutes, total operations, and number of weather days. Specific clusters were defined based on the variance of the key metrics. In the 5-cluster analysis, the selected days are: February 28, 2006 (High volume, low weather), April 5, 2006 (High volume, medium weather), October 21, 2006 (Low volume, low weather), 
June 24, 2006 (Low volume, medium weather), and April 3, 2006 (High volume, high weather). The analysis also defined two baseline days with clear weather: January 7, 2006 (low traffic volume) and February 28, 2006 (high traffic volume) to perform or start

simulations with clear weather.

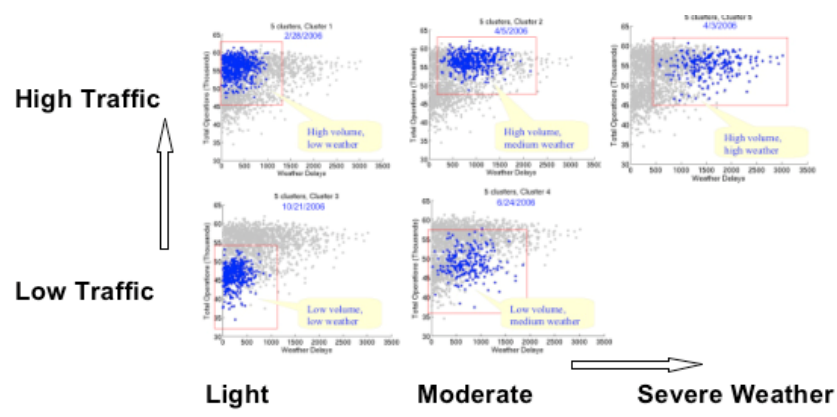

Figure 5-5-Cluster Analysis

Figure 5 shows a cross-sectional view of the 5-cluster days in 2006 as a function of "Weather Delays" as a metric of weather versus "Total number of operations" as a metric of air traffic.

\section{SUMMARY/CONCLUSIONS}

SLDAST has been chartered to assess the benefits of NextGen concepts and technologies and to pursue a research focus on baseline research, design studies, and system-level assessments with a set of milestones. In 2009, SLDAST accomplished the Common Definitions, Human Factors Assessment, and Multi-Sector Planner Concept of Operations milestones. The progress on the design studies and assessments developed the common scenarios, including the technology changes from Baseline (2006) through NGIP (2018), and NextGen (2025) with increasing traffic demands as described under the NextGen Implementation Plan for 2018 and NextGen for 2025 ..

The SLDAST design studies have been defined and progress with SA-TFM simulations, DAC-TFM and System-Level Assessment I implementation, which together with the scenarios, metrics and assumptions developments in ACES provide the basis for the required assessments.

Finally, it is fair to state that this paper only describes a small set of the program and only a reduced set of the SLDAST research accomplished in 2009 and substantial research developed by a large number of researchers is not included.

\section{REFERENCES}

1. Next Generation Air Transportation System Integrated Plan, JPDO, December 2004.

2. Federal Aviation Administration, "FAA's NextGen Implementation Plan," Washington, DC, March 2011.

3. Airspace Systems program, Program Plan, version 1.0, NASA, May 2010.

4. Airspace Systems Program, Fact Sheet (2011) Updated, NASA, NF-2011-02-533-HQ, http://www.aeronautics.nasa.gov/programs_asp.htm, 2011.

5. Airspace Concept Evaluation System (ACES), http://www.aviationsystemsdivision.arc.nasa.gov/research/modeling/aces.shtml.

6. Federal Aviation Administration, "FAA's NextGen Implementation Plan," Washington, DC, June 2008.

7. Federal Aviation Administration, "FAA's NextGen Implementation Plan 2009," Washington, DC, revised on February 10, 2009

8. Concept of Operations for the Next Generation Air Transportation System, v. 2.0, Joint Planning and Development Office, June 13, 2007.

9. Smith, J.C., and K,W. Neitzke, "Metrics for the NASA Airspace Systems," NASA/SP-2009-6115, 2009.

10. Funk, K., R. Mauro, and I. Barshi, "NextGen Flight Deck Human Factors issues," 2009 International Symp. on Aviation Psychology, Dayton, OH, April 2009.

11. Funk, K. "A Methodology and Tools for the Prospective identification of Human Factors issues," 2009 International Symp. on Aviation Psychology, Dayton, OH, April 2009.

12. C. D. Cabrall, L. H. Martin, P. U. Lee, \& K. K. Jobe, "Exploration of human factors issues within a future separation assurance concept," Digital Avionics and Systems Conference, Orlando, FL, Oct. 28, 2009. 
13. Klein, A., Rogers, M., and Kaing, H. (2008). Dynamic FPAs: A New Method for Dynamic Airspace Configuration. Integrated Communications Navigation and Surveillance (ICNS) Conference. Bethesda, MD.

14. Xue, M., “Airspace Sector Redesign Based on Voronoi Diagrams," AIAA J. of Aerospace Computing, Sep. 2008.

15. Sridhar, B., Grabbe, S., and Mukherjee, A., "Modeling and Optimization in Traffic Flow Management" Proceedings of the IEEE, Vol. 96, No. 12, Dec. 2008.

16. Erzberger, H.: "'The Automated Airspace Concept," 4th USA/Europe Air Traffic Management RI\&D Seminar, Santa Fe, NM, USA, 3--7 Dec. 2001.

17. Erzberger, H., and R.A. Paielli, "Concept for Next Generation Air Traffic Control System,"” Air Traffic Control Quarterly, 10, 4, 2002, pp 355-378.

18. Meyn, L. A., "Nation-Wide Simulation of En-route Aircraft Conflicts," 9th AIAA Aviation Technology, Integration, and Operations Conference in Hilton Head, South Carolina, September 21-23, 2009.

19. Russell, C. R., "Expanding Regional Airport Usage to Accommodate Increased Air Traffic Demand," 9th AIAA Aviation Technology, Integration, and Operations Conference in Hilton Head, South Carolina, September 21-23, 2009.

20. Palopo, K., Windhorst, R., Suharwardy, S. and Lee, H., "Wind-Optimal Routing in the National Airspace System," 9th AIAA Aviation Technology, Integration, and Operations Conference in Hilton Head, South Carolina, September 21-23, 2009.

21. Karahan, S., and Windhorst, R., "Convective Weather Avoidance with Uncertain Weather," 9th AIAA Aviation Technology, Integration, and Operations Conference in Hilton Head, South Carolina, September 21-23, 2009.

22. Saraf, A. P., Schleicher, D. S., Cheng, V. H. L., Griffin K., Yu, P., Ashok, S., Bushman, J., "Fast and Efficient Method for Generating Airport Models to Support National Airspace System Analyses," AIAA Modeling and Simulation Technologies Conference, Chicago, IL, 10-13 August, 2009.

23. Lee, T., Hunter, G., "Testing and Validation of NextGen Simulators," AIAA Guidance, Navigation, and Control Conference, Chicago, IL, 10-13 August, 2009.

24. Saraf, A. P., Schleicher, D. S., Griffin K., Yu, P., “ Assessment of Potential Benefits of an Ideal Integrated Metroplex-wide Departure Planner," AIAA Aviation Technology, Integration, and Operations Conference, Hilton Head, SC, 21-23 September, 2009.

25. Hunter, G., "NAS-wide Dynamic Resectorization Preliminary Results," Digital Avionics Systems Conference, Orlando, FL, 2529 October, 2009.

26. Gao, H., Hunter, G., “NextGen User Gaming Preliminary Investigation,” Digital Avionics Systems Conference, Orlando, FL, 2529 October, 2009.

27. Cheng, V.H.L., "Trajectory Design for Aircraft Taxi Automation to Benefit Trajectory Based Operations," submitted to the 7th Asian Control Conference, Hong Kong, August 27-29, 2009.

28. Cheng, V.H.L., A. D. Andre, and D. C. Foyle, "Information Requirements for Pilots to Execute 4D Trajectories on the Airport Surface," submitted to the 9th AIAA Aviation Technology, Integration, and Operations Conference (ATIO), Hilton Head, SC, September 21-23, 2009.

29. Kim, J., Tandale, M. D. and Menon, P. K, “Air Traffic Uncertainty Models for Queuing Analysis,” submitted to the 9th AIAA Aviation Technology, Integration, and Operations Conference (ATIO), Hilton Head, SC, September 21-23, 2009.

30. Tandale, M.D., V. Kumar, J. Kim, and P.K. Menon, "Queuing Models for Analyzing the Impact of Trajectory Uncertainties on the NAS Flow Efficiency," submitted to the 9th AIAA Aviation Technology, Integration, and Operations Conference (ATIO), Hilton Head, SC, September 21-23, 2009.

31. Cheng, V.H.L., G.D. Sweriduk, A.Y. Seo, J.C. Yeh, A. Saraf and D.R. Schleicher, "Process and Software Tools for Generating Airport Models to Support Surface Operation Analyses," submitted to the AIAA Modeling and Simulation Technologies Conference, Chicago, IL, August 10-13, 2009.

32. Cheng, V.H.L., A.Y. Seo, W. Wei, and D. Davis, "Embedded Fast-Time Simulation to Support Airport Surface Operation Optimization," submitted to the AIAA Modeling and Simulation Technologies Conference, Chicago, IL, August 10-13, 2009.

33. Cheng, V.H.L., G.D. Sweriduk, V.V.S.S. Vaddi, A.Y. Seo, and P.D. Abramson, "Evaluation of Selected NextGen Concepts for the 2018 Time Frame," submitted to the 9th AIAA Aviation Technology, Integration, and Operations Conference (ATIO), Hilton Head, SC, September 21-23, 2009.

34. Jakobovits, R., Krozel, J., and Kicinger, R., "Traffic Flow Management Algorithms for Setting up Super-Dense Operations,” Air Traffic Control Quarterly, Spring, 2009.

35. Krozel, J., Prete, J., Mitchell, J.S.B., Zou, J., and Kim, J., "Comparison of Flexible, Performance-based Route Planning Algorithms for Super-Dense Operations," Air Traffic Control Quarterly, Spring, 2009.

36. Steiner, M., and J. Krozel, "Translation of Ensemble-based Weather Forecasts into Probabilistic Air Traffic Capacity Impact," submitted to: 8th USA/Europe Air Traffic Management Research and Development Seminar, Napa, CA, June/July, 2009.

37. Steiner, M., Bateman, R., Megenhardt, D., Liu, Y., Xu, M.., and J. Krozel, "Translation of Weather Information into Air Traffic Management Impact - An Ensemble Approach,” submitted to: Air Traffic Control Quarterly, Spring, 2009.

38. Zou, Jason, Kim, Joondong, Mitchell, J.S.B. and J. Krozel, "Flexible, Tree-based Route Planning for Transition Airspace," to be submitted to: Air Traffic Control Quarterly, Spring, 2009.

39. Krozel, J., Mitchell, Yang, S., Polishchuk, V., Jason and Joondong "Flow Rates for Capacity Estimation in Level Flight with Hard 
and Soft Airspace Constraints," submitted to: Air Traffic Control Quarterly, Spring, 2009.

40. Lindholm, T., J. Krozel, and J.S.B. Mitchell, "Concept of Operations for Addressing Multiple Types of En Route Hazardous Weather Constraints in NextGen," AIAA Aviation Technology, Integration, and Operations (ATIO) Conf., Hilton Head, SC, Sept., 2009.

41. Krozel, J., P. Robinson, B. Buck, and D. Wang, "Modeling and Feedback of Turbulence Hazards based on Automated Real-time Pilot Reports," AIAA Guidance, Navigation, and Control Conf., Chicago, IL, Aug., 2009.

42. Klimenko, V., and J. Krozel, "Impact of Clear Air Turbulence Weather Hazards on Air Traffic Management," AIAA Guidance, Navigation, and Control Conf., Chicago, IL, Aug., 2009.

43. Krishna, S., and J. Krozel, "Impact of Icing Weather Hazards on Air Traffic Management," AIAA Guidance, Navigation, and Control Conf., Chicago, IL, Aug., 2009.

44. Kim, J., J. Zou, J. Krozel, and J.S.B. Mitchell, "Sensitivity of Capacity Estimates given Convective Weather Constraints," AIAA Guidance, Navigation, and Control Conf., Chicago, IL, Aug., 2009.

45. Zou, J., J. Krozel, et al, "Two Methods for Computing Directional Capacity given Convective Weather Constraints," AIAA Guidance, Navigation, and Control Conf., Chicago, IL, Aug., 2009.

46. S. Penny, T. Lewis, B. Hoffman, T. White, and J. Krozel, "Cluster Analysis for the Annualization of ACES Simulated NAS Metrics," Metron Aviation, Dulles, VA, January 31, 2009.

\section{CONTACT INFORMATION}

JORGE BARDINA, Ph.D., is a research scientist in the Intelligent Systems Division at NASA Ames Research Center. His areas of interests are real-time collaborative environments, web-based and parallel architectures, intelligent systems, modeling, simulation, and engineering technologies. Author of over 80 publications in the areas of intelligent systems, information sciences, aeronautics, aerothermodynamics, computational fluid dynamics and turbulence. Dr. Bardina received his Civil Engineering of Industries with Mechanical Mention degree from Universidad Catolica de Chile and his Ph.D. degree and M.S. degree on Mechanical Engineering and M.S. degree in Economics from Stanford University.

Jorge.E.Bardina@nasa.gov

\section{ACKNOWLEDGMENTS}

This paper describes the program and the SLDAST research conducted in 2009 while the author was one of the two Associated Principal Investigators of SLDAST. Therefore, the program development and the research accomplished describe the contributions of of a large number of researchers, and the author acknowledges their contributions. The author acknowledges the contributions at the program level of Thomas Davis, Robert Windhorst, Richard Barhydt, Parimal Kopardekar, and Michael Landis. and the research contributions of Larry Meyn, Kee Palopo, Jeremy Smith, Michael Downs, Immanuel Barshi, Louis Freund, Paul Lee, Paul Abramson, Ed Koenke, Jimmy Krozel, Victor Cheng, David Schleicher, and George Hunter.

\section{DEFINITIONS/ABBREVIATIONS}

$\begin{array}{ll}\text { ACES } & \text { Airspace Concept Evaluation System } \\ \text { ASP } & \text { Airspace Systems Program } \\ \text { CTD } & \text { Concepts and Technology Development } \\ \text { DAC } & \text { Dynamic Airspace Configuration } \\ \text { FAA } & \text { Federal Aviation Federal Aviation Administration } \\ \text { JPDO } & \text { Joint Planning and Development Office } \\ \text { MIDAS } & \text { Man-machine Integrated Design and Analysis System } \\ \text { NAS } & \text { National Air Space } \\ \text { NASA } & \text { National Aeronautics and Space Administration } \\ \text { NextGen } & \text { Next Generation Air Transportation System } \\ \text { RFA } & \text { Research Focus Area } \\ \text { SA } & \text { Separation Assurance } \\ \text { SAIE } & \text { Systems Analysis, Integration \& Evaluation } \\ \text { SDO } & \text { Super Density Operations } \\ \text { SESO } & \text { Safe and Efficient Surface Operations } \\ \text { SLDAST } & \text { System-Level Design, Analysis, and Simulation Tools } \\ \text { TFM } & \text { Traffic Flow Management }\end{array}$

